\title{
Turismo Esportivo: um estudo de caso sobre o Ultimate Fighting Championship (UFC) 198 em Curitiba - Brasil
}

Jonathan Rocha de Oliveira ${ }^{\mathrm{a}}$ Bruna Opieco Pereirab Riqueldi Straub Lise André Mendes Capraro

\section{Resumo}

OEste estudo investigou os dados fornecidos pela Prefeitura Municipal de Curitiba, pelo Instituto Municipal de Turismo de Curitiba em parceria com o Observatório de Turismo do Paraná e o Observatório do Turismo do Rio de Janeiro, pelo Jornal Gazeta do Povo e pelo website do Clube Athletico Paranaense para compreender os fatores que tornaram o evento esportivo do UFC 198 um atrativo turístico bem-sucedido em Curitiba. Os resultados indicaram que o evento gerou, direta e indiretamente, cerca de $\mathrm{R} \$ 45$ milhões e influenciou positivamente o fluxo turístico na cidade. Cerca de $45 \mathrm{mil}$ pessoas compareceram ao estádio no dia do evento, das quais $42,37 \%$ eram turistas e $8,49 \%$, excursionistas, que vieram de 22 estados e do Distrito Federal. Em contraste, a taxa de turistas internacionais foi pouco significativa (2,6\%). As características da cidade sede influenciaram o sucesso do evento, como a alcunha de "solo sagrado das artes marciais", além da estrutura já instaurada por conta de eventos anteriores, como o estádio construído para a Copa do Mundo da Fifa, em 2014. Por fim, a atuação do governo municipal e estadual não foi significativa e, se tivesse sido mais relevante, o evento poderia ter gerado ainda mais benefícios.

Palavras-chave: Turismo esportivo; Evento; MMA; UFC 198; Curitiba.

\section{Abstract \\ Sports Tourism: a case study about the Ultimate Fighting Championship (UFC) 198 in Curitiba (Brazil)}

This study investigated the data provided by the Curitiba City Hall, the Curitiba Municipal Tourism Institute in partnership with the Paraná Tourism Observatory and the Rio de Janeiro Tourism Observatory, the Gazeta do Povo newspaper, and Clube Athletico Paranaense's website, seeking to understand why the UFC 198 event could be considered a successful tourist attraction in the city of Curitiba. The results indicated that the event generated, directly and indirectly, $\mathrm{R} \$ 45$ million, and influenced positively in the tourist flow of the city. Around 45,207 people were present in the stadium, $42.37 \%$ of them were tourists and $8.49 \%$ were hikers, coming from 22 Brazilian states and the Federal District. In contrast, the international tourist demand had little significance

a. Mestrando em Educação Física pela Universidade Federal do Paraná (UFPR), Curitiba, Paraná, Brasil. E-mail: jonathan.cwb3@gmail.com

b. Mestre em Educação Física pela Universidade Federal do Paraná (UFPR), Curitiba, Paraná, Brasil. E-mail: brunaopieco@gmail.com

c. Pós-doutorando em Educação Física pela Universidade Federal do Paraná (UFPR), Curitiba, Paraná, Brasil. Docente no curso de Educação Física da Universidade Positivo, Curitiba, Paraná, Brasil. E-mail: liseriqueldi@gmail.com

d. Pós-doutor em História pela Universitá Ca’Foscari Di Venezia, Veneza, Itália. Docente dos cursos de graduação e pós-graduação em Educação Física da Universidade Federal do Paraná (UFPR), Curitiba, Paraná, Brasil. E-mail: andrecapraro@gmail.com 
(2.60\%). The characteristics of the city influenced the success of the event, such as the nickname "sacred ground of the martial arts", beyond the city's established structure due to previous events such as the stadium built for the FIFA World Cup in 2014. To conclude, the presence of the local and state government was not expressive and, had been more relevant, the event could have had even better results.

Keywords: Sport tourism; Event; MMA; UFC 198; Curitiba.

\section{Resumen}

Turismo Deportivo: un estudio de caso sobre el Ultimate Fighting Championship (UFC) 198 en Curitiba (Brasil)

Este estudio investigó los datos proporcionados por el Ayuntamiento de Curitiba, el Instituto Municipal de Turismo de Curitiba en colaboración con el Observatorio de Turismo de Paraná y el Observatorio de Turismo de Río de Janeiro, el periódico Gazeta do Povo y el sitio web del Clube Athletico Paranaense, con el fin de comprender por qué el evento UFC 198 podría considerarse una atracción turística exitosa en la ciudad de Curitiba. Los resultados indicaron que el evento generó, directa e indirectamente, alrededor de los $\mathrm{R} \$ 45$ millones e influyó positivamente en el flujo turístico de la ciudad. Aproximadamente 45.000 personas estuvieron presentes en el evento, de las cuales el 42,37\% eran turistas y el 8,49\% excursionistas, que procedían de 22 estados brasileños y del Distrito Federal. Las características de la ciudad anfitriona influyeron en el éxito del evento bajo el reconocimiento como "terreno sagrado de las artes marciales", además de la estructura de la ciudad establecida en eventos anteriores como la cancha para la Copa del Mundo FIFA en 2014. Para concluir, la presencia del gobierno local y estatal no fue expresiva, y si hubiera sido más relevante, el evento podría tener mejores resultados.

Palabras-Clave: Turismo deportivo; Evento; MMA; UFC 198; Curitiba.

\section{INTRODUÇÃo}

Em 14 de maio de 2016, a cidade de Curitiba sediou o maior evento de Mixed Martial Arts (MMA) já realizado no Brasil - segundo a própria instituição organizadora, o Ultimate Fighting Championship (UFC) 198. Curitiba obteve resultados sensivelmente positivos neste período no tangente ao fluxo nacional de turistas, esgotando a venda dos 45 mil ingressos e alcançando o quarto maior público da história do torneio, ficando atrás apenas de Toronto (2001) e Melbourne (2015 e 2019) (UFC, 2019). Este ocorrido faz sentido à medida em que, ao longo das últimas décadas, um dos principais fomentadores do turismo de ocasião são os eventos - sejam artísticos, políticos, culturais, científicos ou, sobretudo, esportivos (Getz, 2008).

0 turismo esportivo é um fenômeno global e, entre os segmentos da "indústria" turística, é o que vem crescendo mais rapidamente (Brown et al., 2010). Sendo assim, o turismo esportivo, o qual "compreende as atividades turísticas procedentes da prática, envolvimento, ou observação de modalidades esportivas" (Johner \& Cunha, 2016, p. 98), é um dos maiores atrativos de públicos ocasionais 
na atualidade. Este fenômeno pode ser considerado uma experiência cultural, formada pela interação de três fatores: lugar ou espaço, atividade e a(s) pesso$\mathrm{a}(\mathrm{s})$ (Weed, 2008). Assim como outros segmentos do setor, o turismo de eventos esportivos exerce impactos na economia, na sociedade e no ambiente dos locais que os sediam. Tais impactos pode ser maiores de acordo com a relevância da competição em termos de público (Ishy, 1998).

Combates de MMA e boxe, por exemplo, são, regularmente, disputados em Las Vegas, cidade norte-americana construída no estado de Nevada com fins turísticos explícitos. A economia desta cidade é completamente dependente do setor turístico e os eventos esportivos complementam a proposta de entretenimento já existente, em alguns casos até emergem como um dos principais contribuintes para atrair turistas (Brown et al., 2010). Com a infraestrutura hoteleira já consolidada, Las Vegas tem a capacidade de receber relevantes eventos esportivos, sobretudo os pugilísticos e de combates intermodalidades, isto é, aqueles já conhecidos no meio dos apostadores (Brown et al., 2010).

Mesmo existindo um volume significativo de estudos de caso sobre o turismo em eventos e megaeventos esportivos (Brown et al., 2010; Kirilenko \& Stepchenkova, 2017; Rocha \& Fink, 2017), ainda são escassas as pesquisas cuja delimitação espacial seja o Brasil e, ainda mais, cuja modalidade seja o MMA. A proposta deste artigo é analisar os dados fornecidos pela Prefeitura Municipal de Curitiba, por meio do Instituto Municipal de Turismo de Curitiba em conjunto com o Observatório de Turismo do Paraná e o Observatório do Turismo do Rio de Janeiro, pelo jornal Gazeta do Povo e pelo Clube Athletico Paranaense (CAP) - proprietário do estádio em que o evento foi realizado -, na tentativa de compreender porque o evento esportivo pode ser considerado um bem-sucedido atrativo turístico na cidade de Curitiba.

A hipótese elencada para tal sucesso, especialmente na esfera turística, foi a uma conjunção de fatores, tais como: a tradição local na formação de atletas de reconhecimento internacional - como Cris Cyborg, Anderson Silva, Maurício Shogun, entre outros -, o investimento realizado na cidade de Curitiba devido a Copa do Mundo de 2014, bem como o resultado positivo obtido no UFC 134 disputado no Rio de Janeiro em 2011. Ademais, os organizadores acostumados com a realização de eventos itinerantes, tinham a noção do potencial de consumo que a edição 198 do UFC poderia gerar, sobretudo devido ao card - programação das lutas - do evento.

\section{O DESTINO TURÍstICO DE CURITIBA (PARANÁ) - BRASIL}

Segundo Lohmann e Netto (2008), tanto o turista quanto o excursionista podem ser considerados visitantes de um determinado atrativo turístico, contudo, o que os distingue é o fato de que o turista pernoita no destino e o excursionista não dorme no local (cidade) visitado. A capital paranaense recebeu dois milhões e oitocentos mil turistas (nacionais e internacionais) em 2016 - ano de realização do UFC 198 -, ocupando a sétima posição entre os destinos turísticos mais visitados no Brasil, de acordo com um levantamento realizado pelo Geofusion (Geofusion, 2016). E, mais especificamente acerca da chegada anual de excursionistas em Curitiba, não foram encontrados dados sobre o ano de 2016 durante diversas consultas online, tampouco referente a qualquer outro ano até o momento da construção desta pesquisa. 
Ao longo do ano de 2015, o setor de turismo curitibano movimentou $\mathrm{R} \$ 450$ milhões, recebendo aproximadamente 200 mil turistas (RPC, 2016). Cabe frisar que Curitiba não figura entre os destinos brasileiros mais visitados por turistas estrangeiros - estes, por sua vez, preferem locais cuja temperatura elevada e as praias sejam o principal atrativo, como a cidade do Rio de Janeiro, Florianópolis e a costa da região nordeste (Ministério do Turismo, 2016; 2019).

Para Nakatani et al. (2017), a promoção de um destino turístico é uma função, de modo geral, delegada aos organismos públicos do setor, como o Instituto Municipal de Turismo de Curitiba na capital paranaense. Neste sentido, a própria gestão municipal da cidade propagandeou que Curitiba se demonstra cada vez mais preparada para receber eventos de grande porte, após receber eventos como a Copa do Mundo e o UFC 198. Nakatani et al. (2017) comentam que os órgãos oficiais do turismo nesta localidade possuem, de fato, um importante papel na promoção do destino turístico e de seus produtos. Além da criação de espaços (esportivos ou não) que incentivaram novas formas de visitação, Curitiba também participou de diversos eventos nacionais e internacionais buscando aumentar a sua demanda turística (Instituto Municipal de Turismo de Curitiba, 2016a). Por exemplo, de acordo com o ranking de eventos globais (entre segmentos variados das indústrias de mercado) associadas à International Congress and Convention Association (ICCA), a cidade foi palco de seis eventos globais em 2018, ficando em $82^{\circ}$ lugar no ranking entre cidades latino-americanas e na 365 colocação no ranking mundial (International Congress and Convention Association, 2018).

A partir disso, constatou-se que "[...] o incentivo ao turismo de eventos e negócios foi estimulado com apoio a diversos eventos geradores de fluxo turístico, com destaque a realização de jogos e eventos como a Copa do Mundo 2014 FIFA, Ultimate Fighting Championship (UFC), a Conferência Mundial da Saúde e o Desafio Mundial de Resgate, entre outros. 0 turismo na realização de grandes eventos impacta economicamente em mais de 50 segmentos, a começar por hotelaria, comércio, gastronomia" (Instituto Municipal de Turismo de Curitiba, 2018).

Ao observar a possibilidade de um retorno favorável, a partir do investimento em turismo, a Prefeitura Municipal de Curitiba criou nove roteiros temáticos com o objetivo de atingir diferentes grupos, potencialmente interessados em conhecer a cidade. Uma das formas de observar o crescimento no turismo de lazer na localidade é por meio do número de reservas feitas em hotéis nos fins de semana, as quais têm sido maiores em relação aos dias de semana (Instituto Municipal de Turismo de Curitiba, 2018).

Além disso, o clima é um dos fatores naturais relacionados à motivação turística (Machete, 2011) e pode ser aproveitado conforme as suas particularidades tendo em vista que, de acordo com a autora, é um recurso que não será esgotado pelo consumo turístico. Nesse sentido, Curitiba explora o potencial oferecido pela estação mais gelada do ano através de eventos como o "Festival de Inverno de Curitiba", o qual costuma organizar uma programação especial em teatros, restaurantes, hotéis, praças, entre outros pontos da capital.

A exemplo disso, a Prefeitura Municipal de Curitiba promoveu o destino em uma de suas campanhas da seguinte forma: "Uma massa de ar gelado chegou a Curitiba e, com as temperaturas baixas, a expectativa do setor do turismo é que a capital paranaense atraia mais visitantes, sobretudo das regiões mais quentes do 
país. 0 inverno curitibano é um atrativo à parte e o resultado é visível para o setor de hospedagens e gastronomia da cidade" (Prefeitura Municipal de Curitiba, 2018). Considerando que durante o mês de maio - período de realização do UFC 198 - as temperaturas ainda chegam aos 20 graus Celsius na maioria dos dias, o clima da cidade sede do evento possivelmente não tenha sido uma variável que afetou a presença do público.

Partindo da premissa que as informações divulgadas pela imprensa e entidades ligadas ao turismo local acerca do UFC 198 foram majoritariamente positivas, contribuindo para a consagração de Curitiba como palco de megaeventos, como aponta a Curitiba Convention \& Visitors Bureau (CCVB, 2016), levanta-se a seguinte questão: quais os fatores que contribuíram para que o evento obtivesse êxito na dinâmica do turismo local?

\section{PROCEDIMENTOS METODOLÓGICOS}

Esta pesquisa, de cunho qualitativo, tem como objeto de estudo o maior evento de MMA já realizado no Brasil na perspectiva do turismo esportivo. Dessa forma, este trabalho se caracteriza como um estudo de caso, pois, na perspectiva das Ciências Sociais, é uma investigação empírica que estuda um determinado fenômeno contemporâneo em profundidade e sem desconsiderar o seu contexto (Yin, 2014). Vale ressaltar o alerta de Robert Yin (2014), ao enfatizar que nem sempre as particularidades contextuais do fenômeno investigado são facilmente distinguíveis e, nestes casos, recomenda-se a utilização de múltiplas fontes e a triangulações destas. Os autores deste estudo optaram por utilizar fontes documentais e jornalísticas das instituições mencionadas na introdução deste artigo.

Além disso, Ludke e André (2013) afirmam que o estudo de caso pode tratar de um feito simples e específico ou complexo e abstrato, desde que o caso seja bem delimitado, como o turismo esportivo no UFC 198. Se, por um lado, existe a possibilidade de se investigar "múltiplos casos" (Yin, 2014). Por outro, "[...] A pesquisa do tipo estudo de caso caracteriza-se principalmente pelo estudo concentrado em um só caso. Esse estudo é preferido pelos pesquisadores que desejam aprofundar seus conhecimentos a respeito de determinado caso específico" (Raupp \& Beuren, 2006, p. 84). Este tipo de pesquisa torna-se, de fato, uma investigação exaustiva de um objeto, permitindo o seu conhecimento amplo e detalhado (Gil, 2008).

Segundo Gil (2008, p. 58), essa metodologia vem sendo cada vez mais utilizada por pesquisadores sociais, tendo em vista que compreende pesquisas com distintos propósitos: "a) explorar situações da vida real cujos limites não estão claramente definidos; b) descrever a situação do contexto em que está sendo feita determinada investigação; c) explicar as variáveis causais de determinado fenômeno em situações muito complexas que não possibilitam a utilização de levantamentos e experimentos".

Considerando os propósitos apresentados, compreende-se que a presente pesquisa se enquadra nos itens " $b$ " e "c", os quais foram explorados a partir de informações fornecidas pela Prefeitura Municpal de Curitiba, pelo Instituto Municipal de Turismo de Curitiba, pelo jornal local Gazeta do Povo e pelo proprietário do 
local, o CAP. A coleta das fontes documentais e bibliográficas ocorreu inicialmente entre os meses de janeiro e março de 2017. Além disso, os pesquisadores perceberam não somente a necessidade de atualizar algumas fontes obtidas, como também de adicionar novos materiais para a análise. Estas últimas ações de coleta, foram realizadas no período de junho à setembro de 2020.

0 documento referente à pesquisa realizada pelo Instituto Municipal de Turismo de Curitiba e colaboradores - a qual contou com 21 pesquisadores que realizaram 462 entrevistas com visitantes no dia e local do evento -, encontra-se disponibilizado no website do órgão supracitado e foi obtido também junto ao Observatório de Turismo do Paraná (Instituto Municipal de Turismo de Curitiba, 2016b). No que tange os dados fornecidos pelo jornal Gazeta do povo e pelo CAP, ambos foram extraídos por meio das notícias e materiais divulgados online nos websites oficiais destas instituições.

Por conta da origem de alguns dados, foi notada a necessidade de observar a veracidade das informações, evitando um tratamento simplório. Para tanto, utilizou-se a análise de conteúdo proposta por Bardin (2016) e, assim, os procedimentos analíticos foram organizados em três etapas sequenciais:

1) Pré-análise: escolha dos veículos de consulta envolvidos com a divulgação de materiais acerca da realização do UFC 198 (CAP, Gazeta do Povo, Instituto Municipal de Turismo de Curitiba e Prefeitura Municipal de Curitiba); seleção dos dados referentes ao evento; formulação de uma hipótese e objetivo - ações estas que não se sucederam obrigatoriamente.

2)Exploração do material: análise e codificação (tabulação e categorização) de cada documento e notícia coletada, a partir de suas características próprias (de escrita e de contexto).

3) Tratamento dos dados obtidos, a inferência e a interpretação: cruzamentos entre as informações, associando os resultados ao contexto do turismo esportivo e da cidade sede; cálculo de percentuais e médias aritméticas - utilizou-se apenas duas casas decimais para exposição de dados. No entanto, todos os cálculos foram efetuados utilizando todas as casas decimais.

Ao passo que os pesquisadores realizaram o tratamento dos dados, fundamentações teóricas da literatura do turismo esportivo foram incorporadas a análise, visando fomentar a discussão dos resultados.

\section{RESULTADOS}

Sendo a maior edição do Brasil e a quarta maior do mundo, o UFC 198 marcou a história do MMA, reunindo 45.207 pessoas no dia do evento e 15 mil presentes no dia da pesagem - o maior público já registrado em um evento de pesagem do UFC -, contribuindo para a grandiosidade do espetáculo assim como para a movimentação na capital paranaense (Clube Athletico Paranaense, 2016d, 2016b, 2016c). De acordo com o Instituto Municipal de Turismo de Curitiba (2016c), 19.155 pessoas presentes no UFC 198 eram turistas residentes fora da cidade, o que representa $42.37 \%$ do público. Ao todo, $90.90 \%$ destes relataram que o UFC 198 era o principal motivo para visitar Curitiba. 
O evento foi transmitido para 149 países e assistido por aproximadamente 1 bilhão e 250 milhões de telespectadores, sendo que os organizadores efetuaram um pagamento estimado no valor de 1 milhão de reais para o aluguel do estádio Joaquim Américo Guimarães - popularmente conhecido como Arena da Baixada - (O Globo, 2016). No dia 11 de maio de 2016, o estádio do CAP recebeu os treinos abertos dos atletas participantes, contando com a presença de cerca de duas mil pessoas. 0 público acompanhou os treinos em uma área anexa ao estádio, a qual faz parte de um projeto que busca possibilitar o uso do espaço para o acontecimento de diversos eventos (Clube Athletico Paranaense, 2016d).

Não foram somente os combates que movimentaram o UFC 198, algumas atividades para os visitantes foram oferecidas para tornar o evento esportivo mais atrativo. Durante todo os combates e também no dia da pesagem, os espectadores puderam participaram de atividades especiais nos corredores do estádio, como sessões de autógrafos com a presença de alguns lutadores famosos e fotos personalizadas, incluindo uma réplica do cinturão de campão (Clube Athletico Paranaense, 2016b, 2016c). Além de assistir à pesagem, os espectadores também puderam colocar a bandagem oficial do UFC e participar da sessão de perguntas (do público) e respostas (dos lutadores), promovendo uma interação maior com o público (Clube Athletico Paranaense, 2016c).

Apesar do sucesso da edição realizada em Curitiba, inicialmente não haviam planos para a realização de outra edição do UFC em estádios. Isto porque a companhia foi comprada em 2017 e os novos proprietários pretendiam investir menos e maximizar os lucros, haja vista que havia uma alta demanda por ingressos e intenção era elevar o preço, assim como diminuir a intenção de globalização do evento esportivo (Gazeta do Povo, 2017). Em uma entrevista ao Combate (canal televisivo de esportes de combate) e publicada pela Gazeta do Povo ainda em 2016, o vice-presidente sênior internacional do UFC na época, Joe Carr, descartou um novo evento na Arena da Baixada no ano seguinte (2017) à edição 198. Mais especificamente, Carr afirmou: "Não temos planos para eventos em estádios de futebol em 2017, mas estamos sempre em busca de oportunidades para que isso aconteça. O UFC 198, em Curitiba, foi muito caro para nós, mas achamos que era a coisa certa a se fazer. Foi um dos melhores eventos da história do UFC em todo o mundo, mas é muito difícil de se fazer. Não dá para fazer um daqueles todo ano" (Gazeta do Povo, 2016b).

Por outro lado, o UFC voltou a ser realizado em um estádio de futebol em 2019 na edição 243 no Docklands Stadium (atualmente sob o nome de Marvel Stadium, devido a venda dos Naming Rights) em Melbourne na Austrália, registrando o maior público da história do UFC até o momento (novembro de 2020) com aproximadamente 57 mil pessoas (UFC, 2019). Naquele mesmo ano, o próprio estádio do CAP havia fechado um acordo para sediar mais uma vez o evento do UFC, desta vez a edição 237 agendada para maio (2019). Contudo, o evento foi transferido para o Rio de Janeiro, devido a divergências na distribuição da renda na venda de ingressos e a baixa expectativa de público - pois os lutadores brasileiros estavam "em queda" e a carência de uma renovação de ídolos no UFC -, de acordo com as palavras do presidente do Conselho Deliberativo no CAP na época e figura influente no clube, Mario Celso Petraglia (Gazeta do Povo, 2019).

Não obstante, a edição do UFC 198 motivou o CAP a intensificar a utilização do seu estádio como sede de outros eventos esportivos. A exemplo disso, quatro 
meses depois a Arena da Baixada sediou o "desafio de ouro" entre a seleções de voleibol do Brasil e de Portugal (Clube Athletico Paranaense, 2016a); recebeu todas as partidas da Liga Mundial de Voleibol em 2017, que durante os quatro dias de realização contou com a presença de 70 mil pessoas ao total (Clube Athletico Paranaense, 2017b); e, ainda, chegou a negociar um acordo para sediar um evento principal concorrente do UFC em 2018, o Bellator, todavia, a parceria com a organização não se concretizou (Gazeta do Povo, 2018). Salienta-se que o estádio também recebe eventos religiosos de grande porte, em 2017 contou com 50 mil pessoas (Clube Athletico Paranaense, 2017a).

Um dos fatores que podem explicar o sucesso do UFC 198, especialmente como um evento esportivo e turístico, foi a presença significativa de visitantes não residentes na cidade, sendo que 18.657 (41.27\% do público total) dos turistas residiam no Brasil e outros 498 turistas (1.10\% do público total) vieram de outros países. Já os 3.840 excursionistas representaram 8.49\% do público presente (Instituto Municipal de Turismo de Curitiba, 2016b). Com mais da metade do público composto por visitantes residentes fora da região de Curitiba, torna-se relevante diagnosticar a localidade de origem destes indivíduos. Neste sentido, o Gráfico 1 apresenta a perspectiva nacional dos turistas no UFC 198, mais especificamente relaciona aos principais estados emissores de turistas e excursionistas.

Gráfico 1 - Representatividade por estado dos visitantes no UFC 198.

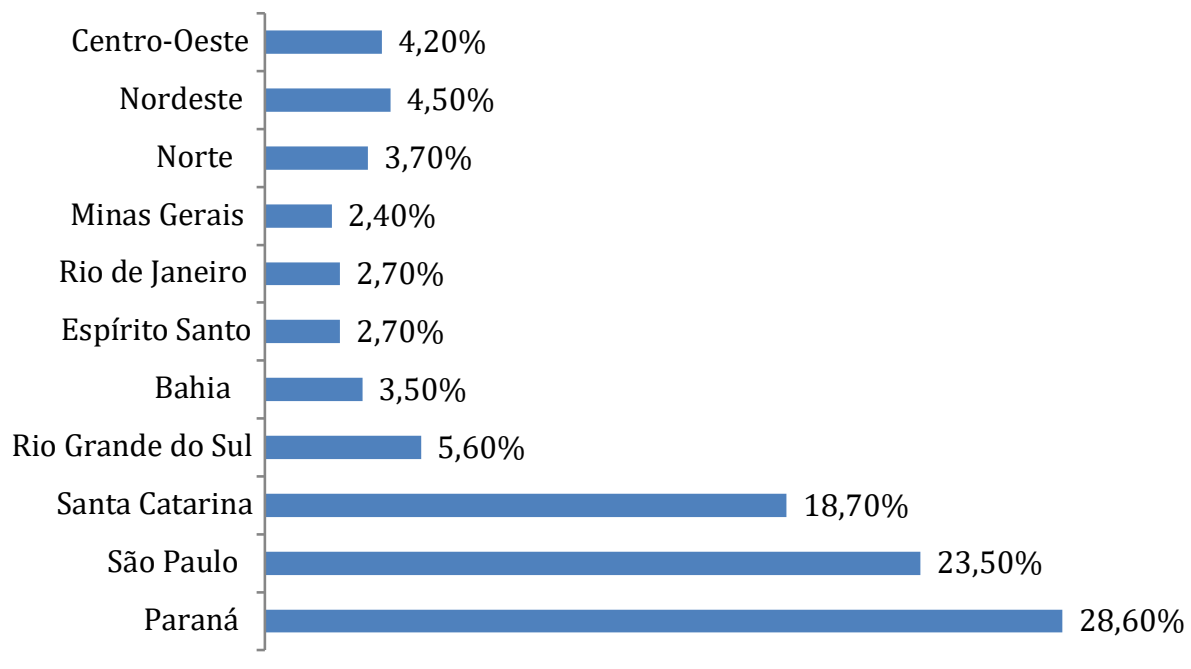

Fonte - Instituto Municipal de Turismo de Curitiba (2016b).

Observa-se que o UFC 198 atraiu visitantes de todas as cinco macrorregiões do Brasil, de 22 estados e do Distrito Federal. Assim, prevaleceu a presença dos turistas residentes no estado do Paraná, São Paulo e em Santa Catarina, pois juntos somam $70.80 \%$ do total de turistas do UFC 198 residentes no país sede. Outra parcela relevante, embora substancialmente inferior aos três estados supracitados, foi identificada em visitantes dos estados do Rio Grande do Sul, Bahia, Espírito Santo, Rio de Janeiro e Minas Gerais que, respectivamente, que juntos somaram $16.9 \%$ do público presente. Cabe mencionar que os visitantes domésticos restantes vieram de outros 14 estados e do Distrito Federal, os quais foram aglomerados no Gráfico (1) de acordo com as suas macrorregiões. Isto porque estes apresentaram um percentual inferior a 2\%, a saber: Distrito Federal 
(1.60\%), Pará (1.60\%), Pernambuco (1.60\%), Goiás (1.10\%), Alagoas (0.80\%), Amazonas (0.80\%), Mato Grosso do Sul (0.70\%), Piauí (0.80\%), Ceará $(0.50 \%)$, Mato Grosso (0.80\%), Paraíba (0.50\%), Roraima (0.50\%), Tocantins $(0.50 \%)$, Maranhão (0.30\%) e Rondônia (0.30\%).

Outro aspecto relevante constatado pelo Instituto Municipal de Turismo de Curitiba (2016b), se refere ao país de residência dos turistas presentes no evento. Identificou-se que houve uma baixa proporção de turistas estrangeiros, pois apenas $2.60 \%$ dos turistas eram de outros países, ou seja, somente 498 pessoas entre os 19.155 turistas no UFC 198. Estes turistas estrangeiros residiam no Paraguai $(0.80 \%)$, Espanha $(0.30 \%)$, Argentina (0.30\%), Chile (0.30\%), Inglaterra $(0.30 \%)$, Coreia do Sul (0.30\%), Bolívia (0.30\%) e Irlanda (0.30\%). De acordo com os dados, $77.90 \%$ do público geral no evento foi composto pelo sexo masculino e $22.10 \%$ pelo sexo feminino (Instituto Municipal de Turismo de Curitiba, 2016b). A principal motivação dos turistas para visitarem Curitiba ressaltaram que o UFC 198 foi o principal objetivo, fato indicado por $90.90 \%$ dos turistas, enquanto $1.80 \%$ tinham o objetivo de assistir um lutador especificamente e os demais estavam na cidade por questões profissionais, visitar parentes e amigos, ou ainda com o propósito de lazer (Instituto Municipal de Turismo de Curitiba, 2016b).

A maioria dos visitantes (63.20\%) ficou hospedada em hotéis, enquanto $24.30 \%$ ficaram em casa de amigos ou parentes, $2.30 \%$ em albergues, $2.00 \%$ em apartamento ou casa alugada, $1.80 \%$ em casa própria, $0.50 \%$ em Airbnb e $5.70 \%$ em locais alternativos como carros, rodoviárias e aeroportos (Instituto Municipal de Turismo de Curitiba, 2016b). 0 tempo de permanência dos visitantes, ilustrado a seguir (Gráfico 2), demonstra o impacto que o evento causou nos meios de hospedagens supracitados.

Gráfico 2 - Tempo de permanência dos espectadores visitantes no UFC 198 em Curitiba.

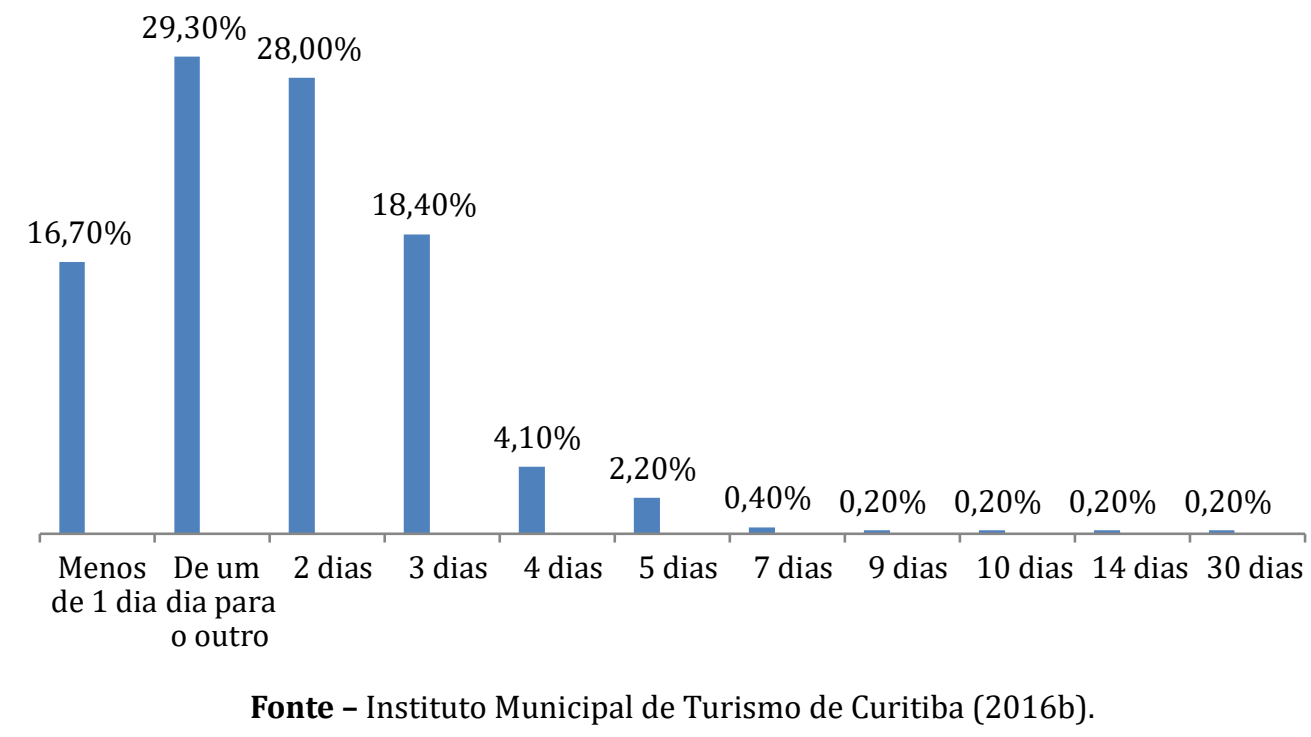

Os resultados apontaram que a maior parte dos visitantes (75.70\%) permaneceu entre um e três dias. Já a média geral de pernoitações foram de três dias. Vale frisar ainda que mais da metade destes (53.90\%) permaneceu minimamente mais de dois dias em Curitiba após o evento e também que $1.20 \%$ dos turistas passou mais de uma semana. Ademais, o período de permanência 
dos excursionistas na cidade (menos de um dia) representou $16.70 \%$ das estadias entre todos os visitantes do evento.

0 evento recebeu avaliações dos visitantes em oito critérios para identificar a percepção dos turistas em relação a experiência turística proporcionada pela organização e estrutura do UFC 198. Conforme exposto na Tabela 1, tais avaliações foram coletadas a partir da Escala de Likert, a qual 0 representa péssima e 10 excelente.

Tabela 1 - Avaliação da experiência turística dos visitantes no UFC 198.

\begin{tabular}{|l|c|}
\hline Critério & Avaliação Média \\
\hline $\begin{array}{l}\text { Prestação de informações sobre o evento (programação, website, } \\
\text { credenciamento e entrada) }\end{array}$ & 8.46 \\
\hline Localização, vagas de estacionamento e facilidades de acesso & 8.46 \\
\hline Níveis de preços dos ingressos e estacionamento & 6.26 \\
\hline $\begin{array}{l}\text { Acessibilidade para pessoas com deficiência ao evento (rampas, } \\
\text { calçadas rebaixadas e chão sinalizado) }\end{array}$ & 9.36 \\
\hline Sinalização para chegar/entrar ao evento & 7.68 \\
\hline Filas na entrada do evento & 8.94 \\
\hline Segurança percebida para chegar ao evento & 8.34 \\
\hline Horários de programação do evento & 8.58 \\
\hline
\end{tabular}

Fonte - adaptado de Instituto Municipal de Turismo de Curitiba (2016b).

De modo geral, as avaliações de organização e estrutura foram positivas, mantendo uma média geral de 8.26 pontos (em uma escala de 0 a 10). A menor nota (6.26) foi atribuída aos preços dos ingressos e dos estacionamentos, enquanto que a maior nota (9.36) foi obtida na avaliação acerca da acessibilidade para pessoas com eficiência ao evento. Os demais quesitos mantiveram-se próximos a média geral. A experiência turística como um todo, isto é, do começo ao fim da viagem, também foi avaliada pelos visitantes que atribuíram uma média de 9.24 na mesma escala de 0 a 10 (Instituto Municipal de Turismo de Curitiba, 2016b).

Essa mesma pesquisa indicou que $96.90 \%$ dos turistas presentes em Curitiba retornariam a cidade para outro evento do UFC e $98.50 \%$ indicariam a cidade para receber novamente o evento (Instituto Municipal de Turismo de Curitiba, 2016b). Tanto a cidade de Curitiba como o evento UFC 198 foram avaliados (por meio de comentários) para estabelecer os seus pontos positivos e negativos percebidos pelos visitantes.

Em síntese, a maioria dos comentários foram positivos. Acerca destes, os principais fatores destacados sobre Curitiba foram sobre a beleza, limpeza, segurança e a organização da cidade, bem como a hospitalidade da população. 0 clima de Curitiba foi considerado frio e agradável. A captação do evento para a cidade foi aprovada pela maioria dos visitantes. Estes visitantes afirmaram que a cidade necessitaria de mais eventos como o UFC 198 (Instituto Municipal de Turismo de Curitiba, 2016b).

Por outro lado, os comentários negativos mais relevantes, embora minoria, acusaram o valor do estacionamento no estádio e nas suas cercanias, a insuficiência de policiamento no local do evento e a falta de informações/orientações por 
parte dos policiais presentes. Além disso, houve comentários negativos apontando para a pouca sinalização para a chegada ao evento, falta de bares e restaurantes próximos ao estádio, a falta de lixeiras, o excesso de semáforos no trânsito, bem como a falta de táxis e de falta de informações sobre o transporte público. Mais especificamente acerca do evento, as principais reclamações foram a dificuldade na compra dos ingressos e a falta informações para retirá-los (Instituto Municipal de Turismo de Curitiba, 2016b).

Além do valor do ingresso para o evento, os turistas também consumiram em hospedagem, alimentação, transporte, entre outras necessidades identificadas em um período médio de estadia de 3.2 dias para os turistas nacionais e 3.7 dias para os turistas internacionais. A Tabela 2 apresenta esses gastos, de acordo com a média individual (diária e durante toda a estadia) e o valores totais gastos pelos turistas no geral (por dia e durante toda a estadia), subdividindo-os em nacionais e internacionais. Tais resultados foram baseados na quantidade de turistas (já mencionada) presentes no evento.

Tabela 2 - Gastos dos turistas no UFC 198 por categoria.

\begin{tabular}{|c|c|c|c|c|}
\hline \multirow{2}{*}{$\begin{array}{l}\text { CATEGORIA } \\
\text { Gasto por } \\
\text { indivíduo }\end{array}$} & \multicolumn{2}{|c|}{ TURISTA NACIONAL (N= 18.657) } & \multicolumn{2}{|c|}{ TURISTA INTERNACIONAL $(\mathrm{N}=498)$} \\
\hline & Média diária & $\begin{array}{l}\text { Média da estadia } \\
\text { completa (3,2 dias) }\end{array}$ & Média diária & $\begin{array}{c}\text { Média da estadia } \\
\text { completa }(3,7 \text { dias })\end{array}$ \\
\hline Hospedagem & $\mathrm{R} \$ 85,84$ & $\mathrm{R} \$ 274,70$ & $\mathrm{R} \$ 179,28$ & $\mathrm{R} \$ 663,33$ \\
\hline Alimentos & $\mathrm{R} \$ 91,68$ & $\mathrm{R} \$ 293,39$ & $\mathrm{R} \$ 135,76$ & $\mathrm{R} \$ 502,32$ \\
\hline Compras & $\mathrm{R} \$ 85,57$ & $\mathrm{R} \$ 273,83$ & $\mathrm{R} \$ 283,15$ & $\mathrm{R} \$ 1.047,66$ \\
\hline Transporte & $\mathrm{R} \$ 56,53$ & $\mathrm{R} \$ 180,91$ & $\mathrm{R} \$ 75,47$ & $\mathrm{R} \$ 279,25$ \\
\hline Outros gastos & $\mathrm{R} \$ 32,36$ & $\mathrm{R} \$ 103,58$ & $\mathrm{R} \$ 8,00$ & $\mathrm{R} \$ 29,60$ \\
\hline $\begin{array}{l}\text { Todas as } \\
\text { categorias }\end{array}$ & $\mathrm{R} \$ 352,01$ & $\mathrm{R} \$ 1.126,43$ & $\mathrm{R} \$ 681,67$ & $\mathrm{R} \$ 2.522,18$ \\
\hline Gasto geral & Total diário & $\begin{array}{c}\text { Total da estadia } \\
\text { completa }(3,2 \text { dias })\end{array}$ & Total diário & $\begin{array}{c}\text { Total da estadia } \\
\text { completa }(3,7 \text { dias })\end{array}$ \\
\hline Hospedagem & $\mathrm{R} \$ 1.601 .610,10$ & $\mathrm{R} \$ 5.125 .152,34$ & $\mathrm{R} \$ 89.281,48$ & $\mathrm{R} \$ 330.341,49$ \\
\hline Alimentos & $\mathrm{R} \$ 1.710 .605,51$ & $\mathrm{R} \$ 5.473 .931,65$ & $\mathrm{R} \$ 67.609,58$ & $\mathrm{R} \$ 250.155,46$ \\
\hline Compras & $\mathrm{R} \$ 1.596 .559,10$ & $\mathrm{R} \$ 5.108 .989,14$ & $\mathrm{R} \$ 141.010,44$ & $\mathrm{R} \$ 521.738,65$ \\
\hline Transporte & $\mathrm{R} \$ 1.054 .811,44$ & $\mathrm{R} \$ 3.375 .396,62$ & $\mathrm{R} \$ 37.586,11$ & $\mathrm{R} \$ 139.068,64$ \\
\hline Outros gastos & $\mathrm{R} \$ 603.907,07$ & $\mathrm{R} \$ 1.932 .502,63$ & $\mathrm{R} \$ 3.984,20$ & $\mathrm{R} \$ 14.741,56$ \\
\hline $\begin{array}{l}\text { Todas as } \\
\text { categorias }\end{array}$ & $\mathrm{R} \$ 6.567 .491,36$ & $\mathrm{R} \$ 21.015 .972,38$ & $\mathrm{R} \$ 339.471,83$ & $\mathrm{R} \$ 1.256 .045,80$ \\
\hline
\end{tabular}

Fonte - Instituto Municipal de Turismo de Curitiba (2016b).

A primeira observação que pode ser realizada na tabela 2, é a de que o turista internacional gastou, relativamente, mais dinheiro que o turista nacional. A superioridade dos gastos destes visitantes estrangeiros foi expressiva na média diária individual nas categorias de alimentação (148.06\%), hospedagem (208.81\%) e compras (330.84\%). Nestas mesmas categorias, tais diferenças cresceram ainda mais ao se comparar a estadia completa entre eles, pois os turistas internacionais 
permaneceram mais tempo em Curitiba que os residentes de outros estados brasileiros. Já a expressiva diferença no gasto total entre o turista internacional e nacional se dá pela presença quantitativamente inferior de turistas internacionais já mencionada anteriormente. Nesse sentido, observou-se uma contribuição econômica direta significativamente superior (94.38\%) dos turistas residentes no Brasil, comparando com os gastos totais de ambos os turistas (nacionais e internacionais), isto é: $\mathrm{R} \$ 22.272 .018,19$. No que tange a categoria transporte, não foram encontradas diferenças significativas.

Tais gastos geraram um impacto econômico relevante para a cidade, tanto de forma direta (valor mencionado acima) quanto indireta ( $\mathrm{R} \$ 22.995 .858,78$ ), totalizando uma injeção financeira de $\mathrm{R} \$ 45.267 .876,97$ em Curitiba por causa do evento (Instituto Municipal de Turismo de Curitiba, 2016b). Essas informações permitem que reflexões sejam feitas em relação ao UFC 198, auxiliando na busca da resposta da problemática proposta nessa pesquisa. Sendo assim, em seguida foram feitas algumas ponderações sobre os resultados obtidos.

\section{DISCUSSÃo}

Pode-se afirmar que os visitantes do UFC 198, dentre as denominações mais difundidas pela literatura acerca do turista esportivo, representaram a porção que se refere aos turistas - e, de certo modo, aos excursionistas - caracterizados como espectadores ou turistas espectadores desportivos (Ferreira \& Silva, 2017; Romano, 2018; Uvinha et al., 2018). Estes visitantes também são reconhecidos como turistas esportivos passivos, pois esta definição pode ser atribuída ao viajante que se desloca a um determinado local para assistir à um evento esportivo ou prática física in loco (Ferreira \& Silva, 2017; Gibson, 1998, 2005; Hall, 1992; Weed, 2006).

Outras duas formas amplamente abordadas pela literatura são: o turista esportivo ativo, ou seja, o indivíduo que viaja para participar (de forma prática) de um evento esportivo - por exemplo, os lutadores presente no card do UFC 198; e o turista esportivo nostálgico, o qual é aquele viajante que se desloca a um destino para contemplar alguma experiência esportiva relacionada ao passado ou locais que se tornaram atrações turísticas após sediar um evento esportivo - não identificado no UFC 198, pois o interesse dos visitantes era pelo evento e não em conhecer o estádio (Ferreira \& Silva, 2017; Frois \& Couto, 2020; Gibson, 1998, 2005; Hall, 1992; Uvinha et al., 2018; Weed, 2006).

Isto posto, identificou-se que o UFC 198 ofereceu uma "experiência turística real do esporte" (Pinheiro, 2012, p. 68) aos seus visitantes e ainda gerou impactos econômicos relevantes à cidade anfitriã. Apesar dos custos elevados para a sua realização, a edição do UFC 198 apresentou-se como um evento esportivo bem sucedido em diversos aspectos no prisma das atratividades turísticas.

Em primeiro lugar, considerando que o evento ocorreu na cidade de Curitiba, é compreensível que Paraná (especialmente do interior do estado), São Paulo e Santa Catarina tenham sido os estados com maior representatividade de visitantes residentes no Brasil, tendo em vista a proximidade geográfica. Nesta mesma direção, o Paraguai, país que possui fronteira com o estado do Paraná, foi o principal emissor de turistas internacionais. 
Além da distância ao destino, outras determinantes contribuíram para o interesse de turistas e excursionistas no evento, o qual teve mais da metade do seu público composto por visitantes. Uma vez que o nível de comprometimento dos turistas/excursionistas de eventos esportivos é específico a cada modalidade esportiva (Ferreira \& Silva, 2017), as características da própria cidade sede foram favoráveis a realização do evento e potencializaram o interesse de visitantes, sobretudo de apreciadores do MMA. Em um teaser divulgado pelo próprio UFC, a cidade de Curitiba é exaltada como o "solo sagrado das artes marciais" (Gazeta do Povo, 2016a). 0 estudo de Passos et al. (2014) demonstra que Curitiba é um dos polos mais tradicionais e pioneiros do MMA no Brasil. A cultura dos esportes de combate está fortemente imbricada a esta região, onde há diversos centros de treinamento, praticantes e lutadores (alguns mundialmente famosos), e costuma ser palco constante de eventos (de menor porte) de MMA e outros esportes de combate.

Soma-se a isto, a capital paranaense ter sido preparada para receber a Copa do Mundo em 2014, fato que teve como consequência o palco do evento em questão. $O$ espaço negociado com o CAP foi fundamental para a escolha de Curitiba como sede do UFC 198. A Arena da Baixada foi reformada e planejada para se tornar um espaço multifuncional capaz de receber outros tipos de eventos além das partidas de futebol, como, de fato, passou a ocorrer a partir de 2014 (Drula, 2015; Rodrigues et al., 2017). Segundo Ferreira e Silva (2017), ao passar por este processo de modernização, as arenas multiusos aumentam o seu potencial como atrativo turístico e as chances de avaliações positivas dos visitantes.

0 público presente no dia da pesagem e no treino aberto revelou que a dinâmica turística ocorreu além do dia 14, possibilitando um retorno para a cidade sede. Entre os brasileiros presentes no evento, houve um predomínio masculino. Tal condição indica que o MMA é mais apreciado pelos homens. Essa predileção pode estar relacionada ao modo como a masculinidade era compreendida historicamente em sociedades não contemporâneas (Boris \& Bloc, 1996). Estes dados reforçam uma cultura de apreciação dos esportes de combate, ainda, predominantemente masculina, conforme apontam Passos et al. ( 2014) ao analisarem o contexto curitibano.

Outra consequência indireta para o interesse dos visitantes, quando o Brasil sediou os Jogos Olímpicos Rio 2016 naquele mesmo ano, além de outros grandes eventos esportivos sediados no país em anos anteriores (Romano, 2018; Uvinha, 2016). Sendo assim, as capitais brasileiras, sobretudo as cidades-sede, investiram para que estivessem preparadas para receber os turistas. De acordo com o anuário estatístico do Ministério do Turismo de 2017 - ano base de 2016 -, Curitiba foi a terceira cidade mais visitada por turistas internacionais na categoria de "Negócios, Eventos e Convenções", a 15a na categoria "Lazer" e a quinta na categoria "Outros Motivos", consolidando-se como uma dos destinos mais visitados no ano de realização do UFC 198 (Ministério do Turismo, 2017).

Identificou-se também que o UFC 198 foi considerado por turistas e excursionistas o principal motivo para visitar Curitiba, fenômeno intitulado por Gammon e Robinson (2003) como "esporte com turismo". Em outras palavras, os autores sugerem que isto ocorre quando o esporte é o produto principal a ser consumido em uma viagem e não de forma circunstancial ou casual. Por ter sido realizado em um sábado, potencializou-se ainda mais a presença de visitantes com a intenção principal de ir ao evento, uma vez que as viagens turísticas motivadas pelo lazer são mais frequentes aos fins de semana (Ferreira \& Silva, 2017) 
Ainda nesta direção, a motivação é um dos principais fatores que influenciam o processo da decisão de compra ou não dos turistas em relação a um determinado produto turístico, tal como o UFC 198. Existem, ainda, as determinantes de caráter externo (opiniões de amigos, marketing turístico, mídia, fatores políticos, econômicos da origem e do destino) e de âmbito pessoal (renda, saúde, compromissos familiares ou profissionais, experiências passadas) (Lohmann \& Netto, 2008).

Os principais eventos esportivos (e.g. Jogos Olímpicos, Copa do Mundo de futebol, diversas ligas esportivas entre outros) são capazes de atrair a atenção de turistas, fãs e espectadores internacionais (Uvinha et al., 2018). Na esteira destas competições esportivas, as edições do UFC passaram a figurar no rol dos eventos mais destacados da agenda do esporte, especialmente a partir da década passada.

Neste cenário, a quantidade pouco significativa de turistas internacionais - somente $2.60 \%$ entre os visitantes - no UFC 198 foi um dado que chamou atenção. o Brasil é um país que, de modo geral, possui um número relativamente baixo de chegada de turistas estrangeiros, com uma média anual de aproximadamente 6,5 milhões desde 2014. Nos anos subsequentes esta média manteve-se sem alterações relevantes. A título de exemplo, no ano de 2019, tais chegadas corresponderam somente a $0.47 \%$ do fluxo de turistas no mundo (Rabahy, 2019). Mesmo sediando alguns megaeventos esportivos importantes nos últimos anos, como aqueles já mencionados, o número de turistas estrangeiros no país não evoluiu de modo considerável durante e tampouco após este período (Frois \& Couto, 2020; Rabahy, 2019; Romano et al., 2019).

A longa distância dos principais países emissores de turistas (e.g. China, Estados Alemanha, Reino Unido, França e Austrália), como apontado por Rabahy (2019), e a insegurança, promovida por uma imagem internacional negativa do Brasil no exterior, podem ser fatores explicativos para este fenômeno. Segundo Uvinha et al. (2018), a segurança do destino turístico, ao lado da excitação, é um fator chave na estimulação do interesse em se comparecer a um evento esportivo. Se, por um lado, os turistas e excursionistas que foram ao UFC 198 destacaram positivamente este aspecto durante a sua visita à cidade, mesmo com um baixo contingente policial relatado. Por outro, em um contexto mais amplo do cenário brasileiro, a questão da segurança ainda é um ponto crítico. Costa e Herrera (2019) alertam que os turistas internacionais sofrem furtos e roubos no Brasil. Estes autores afirmam que isto não influencia em um decréscimo no fluxo turístico de chegadas internacionais no país. Em contrapartida, os baixos índices de visitantes internacionais revelados neste estudo, bem como os diagnósticos supracitados dos órgãos responsáveis pelo turismo brasileiro indicam que a segurança ainda é uma barreira considerável para a chegada de turistas estrangeiros no Brasil.

Destacaram-se, ainda, comentários positivos acerca de aspectos infra estruturais de Curitiba, enfatizando características da cidade que podem influenciar positivamente na sua imagem e contribuir para a promoção de novos eventos. 0 estudo de Uvinha et al. (2018) indica que a infraestrutura é uma determinante que fomenta um mercado potencial mais forte de turistas de eventos esportivos. Nesse sentido, os visitantes elogiaram principalmente a limpeza, a organização, o clima, a beleza e a hospitalidade da população local.

Acerca deste último fator mencionado, a hospitalidade local comentada pelos turistas pode ter impactado na duração da estadia dos turistas de dois modos: influenciando o prolongamento da estadia destes turistas logo após o evento ou em 
um possível retorno deles à cidade. Isto porque a hospitalidade possui uma associação positiva com o tempo de permanência dos turistas de eventos esportivos (Rocha \& Fink, 2017), o que torna, portanto, a atitude dos residentes locais um dos elementos chave para o sucesso de um evento esportivo (Uvinha et al., 2018).

Não obstante, os turistas pontuaram negativamente alguns aspectos da organização do evento em si, especialmente relatando dificuldades para se obter informações sobre o UFC 198 (i.e. retirada de ingressos e como chegar no estádio), e da sua ligação com a infraestrutura da cidade - baixo contingente policial presente no local do evento, insuficiência de meios alternativos de transporte público e de estabelecimentos para alimentação. 0 conjunto dessas informações indica que as entidades oficiais responsáveis pela promoção de lazer, esporte e turismo na cidade de Curitiba não estavam associadas diretamente ao maior evento de MMA já realizado no Brasil. Isso é algo que se assemelha aos resultados da pesquisa de Frois e Couto (2020), que analisou os desdobramentos para tornar o estádio "Mineirão" - uma das sedes da Copa do Mundo de 2014 - em um importante atrativo turístico na cidade de Belo Horizonte, Minas Gerais. Os autores demonstram que o resultado ficou abaixo das expectativas, pois houve pouca participação dos planejadores estratégicos do turismo dentro dos órgãos públicos responsáveis pela elaboração de políticas públicas para o setor.

Para finalizar, o UFC 198 não constava no calendário de eventos do ano de 2016 do Instituto Municipal de Turismo de Curitiba. Dessa forma foi notada a necessidade de observar a questão a partir de um panorama mais amplo, englobando a realidade política da cidade. Em 2016 foi realizada a eleição do prefeito da cidade de Curitiba para o quadriênio 2017-2020. Compreende-se que esse período de transição entre governos pode resultar na modificação ou até mesmo na descontinuidade de projetos, inclusive de eventos de esporte e turismo (Frois \& Couto, 2020). A descontinuidade pode ocorrer em qualquer fase de uma política pública, sendo que normalmente ocorre na fase de implementação, pois "planos e decisões são adiados, ou alternativas de políticas descartadas, simplesmente porque eram da outra gestão" (Nogueira, 2006, p. 48). É possível que se houvesse uma presença mais influente do poder público na organização do UFC 198, os problemas relatados pelos visitantes - de organização e infraestrutura poderiam ter sido amenizados ou evitados. Cabe frisar que a relação entre o CAP e a Prefeitura Municipal de Curitiba estava enfraquecida na época, por conta de divergências e desacordos após a reforma da Arena da Baixada para a Copa do Mundo de 2014 (Drula, 2015).

\section{CONSIDERAÇÕES FINAIS}

Considerando os dados obtidos e o diálogo com literatura, entende-se que o UFC 198 se consolidou como o maior evento de MMA já realizado no Brasil até o presente momento (2021), pois ocorreu em uma cidade que possui um público interessado no conteúdo oferecido. Além disso, a estrutura de Curitiba, devido a sua preparação para (mega)eventos que foram realizados próximos a data do UFC 198, potencializou o evento como um atrativo turístico bem-sucedido. Podese afirmar que tal estrutura, sobretudo em quesitos de limpeza, segurança e organização, foi um dos fatores determinantes ao interesse dos visitantes. Como 
resultado, observou-se um considerável fluxo turístico (de residentes no Brasil) e uma experiência turística positiva destes visitantes.

A programação do evento foi outro ponto positivo a ser destacado, pois diversos lutadores brasileiros famosos (e alguns nativos) participaram da programação, inclusive disputando o título. A Arena da Baixada também exerceu uma influência positiva, por conta da sua capacidade para receber um público significativo e por ser um espaço destino a um esporte expressivamente popular no Brasil, o futebol. Um alerta que deve ser pontuado, é de que o estádio não faz parte da rota da linha do ônibus de turismo da cidade, mesmo sendo um local de significativa visitação (de excursionistas e turistas) e um região de fácil acesso, próxima ao centro da cidade.

Apesar do sucesso e dos rumores de uma nova edição do UFC na capital paranaense, compreende-se que dois fatores foram preponderantes para que a não realização do evento na cidade até o momento desta pesquisa (2020). Em primeiro lugar, o relato concedido pelo vice-presidente sênior internacional do UFC na época da edição 198, o qual indicou que o custo elevado da organização do evento seria um empecilho para que o mesmo ocorresse novamente no ano seguinte (e em 2019). Em segundo, o fato de que o envolvimento das entidades oficiais responsáveis pela promoção de lazer, esporte e turismo na cidade de Curitiba não foi expressivo.

Deste modo, caso a presença do governo municipal e estadual tivesse sido mais relevante, o evento poderia ter gerado ainda mais benefícios para a cidade, atrair mais turistas ou aumentando o seu tempo de permanência e os gastos destes e, ainda, promover melhor os produtos turísticos da cidade, ou ainda, que uma nova edição do UFC pudesse ter sido realizada posteriormente. Conclui-se que as entidades oficiais responsáveis pela promoção de lazer, esporte e turismo na cidade de Curitiba tiveram papel secundário e ínfimo no projeto. Ou seja, os benefícios elevados, mas abruptos e ocasionais, não foram aproveitados para a criação de uma política municipal sistemática de uso do esporte - no caso o MMA - com atrativo turístico.

Assim como outros (mega)eventos esportivos já realizados nesta e em outras capitais brasileiras, o UFC 198 impactou positivamente na economia, na cultura de eventos esportivos - particularmente, "ressignificando" a utilização da Arena da Baixada (Rodrigues et al., 2017, p. 1287)verifying what influenced the (re ao abranger outras modalidades além do futebol - em Curitiba e na sua promoção como destino turístico. No entanto, tais contribuições não se consolidaram em melhorias permanentes para a infraestrutura da cidade, tampouco do fluxo turístico e dos seus produtos turísticos. Como se sabe, este fenômeno não é novidade no contexto brasileiro, o qual necessita de políticas públicas mais eficientes de segurança, organização, promoção, transporte e desenvolvimento turístico para alavancar o setor no país inteiro, atraindo mais turistas, especialmente os internacionais - sobretudo aqueles turistas residentes nos principais países emissores de turistas, com baixo índice de visitas aos destinos brasileiros - que poderiam aumentar o seu tempo de permanência, frequência das suas visitas e, consequentemente, os seus gastos.

É imprescindível reforçar que o Brasil ainda possui uma imagem pouco atrativa como destino turístico internacional, apesar de ter potencial para exploração e desenvolvimento, e a segurança no país é um fator preponderante neste 
cenário. No UFC 198, os visitantes reclamaram da (baixa) quantidade de policiais no evento, mas elogiaram a segurança da cidade. A partir disso, conclui-se que o evento para servir como referência no que diz respeito a organização e segurança de outros (mega)eventos esportivos no país. Deve-se ponderar que a colaboração e presença de órgãos públicos no planejamento e realização do evento poderia ter melhorado a percepção de segurança dos visitantes, por exemplo, com o aumento de policiais presentes.

A mote de sugestão para futuras pesquisas, a necessidade de novas investigações acerca da parceria dos órgãos públicos com as agências ou instituições promotoras desses eventos esportivos. Outros estudos de casos acerca de eventos esportivos que já ocorreram no Brasil - Copa América de Futebol 2019, edições do UFC em outras cidades brasileiros, bem como torneios e disputas de outros esportes - também podem oferecer possibilidades pertinentes de pesquisa. Tais pautas podem contribuir significativamente para o desenvolvimento e alavancagem do turismo esportivo no país.

\section{REFERÊNCIAS}

Bardin, L. (2016). Laurence Bardin - Análise de Conteúdo. São Paulo: Edições 70.

Boris, G. D. J. B., \& Bloc, L. G. (1996). Violência e masculinidade. In C. B. Daniel (Ed.), Poder e Violência. Fortaleza: EUFC.

Brown, C., Busser, J. A., \& Baloglu, S. (2010). Sport tourists in a gaming destination: predicting gaming and non-gaming expenditures. UNLV Gaming Research \& Review Journal, 14(2), 59-68.

CCVB. (2016). UFC consolida Curitiba como palco de megaeventos. http://www.curitibacvb. com.br/noticia/ufc-consolida-curitiba-como-palco-de-megaeventos

Clube Athletico Paranaense. (2016a). Com partida histórica de vôlei, Estádio Atlético Paranaense amplia conceito multiuso. https://www.athletico.com.br/noticia/41543com-partida-histrica-de-vlei-estdio-atltico-paranaense-amplia-conceito-multiuso/

Clube Athletico Paranaense. (2016b). Estádio Atlético Paranaense entra para a história do UFC. https://www.athletico.com.br/noticia/40566-estdio-atltico-paranaenseentra-para-a-histria-do-ufc/

Clube Athletico Paranaense. (2016c). Estádio Atlético Paranaense recebeu a maior pesagem da história do UFC. https://www.athletico.com.br/noticia/40554-estdio-atlticoparanaense-recebeu-a-maior-pesagem-da-histria-do-ufc/

Clube Athletico Paranaense. (2016d). UFC no estádio atleticano trouxe lucro de $R \$ 45$ milhões para Curitiba. https://www.athletico.com.br/noticia/40664-ufc-no-estdio-atleticanotrouxe-lucro-de-r-45-milhes-para-curitiba/

Clube Athletico Paranaense. (2017a). Estádio Atlético Paranaense recebeu o culto de encerramento da "Semana do Avivamento." https://www.athletico.com.br/noticia/estadio-atleticoparanaense-recebeu-o-culto-de-encerramento-da-semana-do-avivamento/

Clube Athletico Paranaense. (2017b). Estádio Atlético Paranaense sediou a Liga Mundial de Vôlei. https://www.athletico.com.br/noticia/estadio-atletico-paranaense-sedioua-liga-mundial-de-volei/

Costa, J. H., \& Herrera, M. R. G. (2019). Criminalidade, Segurança Pública E Sustentabilidade Em Destinos Turísticos. Marketing \& Tourism Review, 4(1), 1-39. https://doi.org/ 10.29149/mtr.v4i1.5510 
Drula, A. J. (2015). O processo de transformação de um estádio para arena: o caso da "Arena da Baixada". Dissertação (Mestrado em Educação Física) - Programa de Pós-Graduação em Educação Física, Universidade Federal do Paraná.

Ferreira, E. A. M., \& Silva, L. P. da. (2017). Turismo futebolístico: perfil e motivações do torcedor viajante que frequenta o "novo" Mineirão. Revista Brasileira de Ciencias do Esporte, 39(3), 268-275. https://doi.org/10.1016/j.rbce.2017.02.014

Frois, R., \& Couto, A. C. (2020). Megaeventos Esportivos e Turismo : O Pós-Copa do Mundo FIFA 2014 em Belo Horizonte - Brasil. Ateliê do Turismo, 4(1), 29-50.

Gammon, S., \& Robinson, T. (2003). Sport and tourism: A conceptual framework. Journal of Sport and Tourism, 8(1), 21-26. https://doi.org/10.1080/14775080306236

Gazeta do Povo. (2016a). Em teaser, UFC chama Curitiba de "solo sagrado das artes marciais." https://www.gazetadopovo.com.br/vozes/luta-livre/ufc-chama-curitiba-de-solosagrado-das-artes-marciais-em-teaser/

Gazeta do Povo. (2016b). UFC descarta evento na Arena da Baixada em 2017. https://www. gazetadopovo.com.br/blogs/luta-livre/ufc-tera-participacao-discreta-no-brasil-em-2017/

Gazeta do Povo. (2017). Entenda por que Curitiba e a Arena não voltaram a ser prioridade do UFC. https://www.gazetadopovo.com.br/vozes/luta-livre/entenda-por-quecuritiba-e-arena-nao-voltaram-ser-prioridade-ufc/

Gazeta do Povo. (2018). Wanderlei Silva se reúne com o Atlético para fechar megaevento na Arena. https://www.gazetadopovo.com.br/vozes/luta-livre/bellator-arenaatletico-wanderlei-silva/

Gazeta do Povo. (2019). Petraglia explica motivo do UFC desistir de Curitiba. https://www. gazetadopovo.com.br/vozes/luta-livre/petraglia-ufc-de-curitiba/

Geofusion. (2016). Vai e Vem: a população turística no Brasil. https://geofusion.com.br/ imprensa-e-noticias/vai-e-vem-a-populacao-turistica-do-brasil/

Getz, D. (2008). Event tourism: Definition, evolution, and research. Tourism Management, 29(3), 403-428. https://doi.org/10.1016/j.tourman.2007.07.017

Gibson, H. J. (1998). Sport Tourism: A Critical Analysis of Research. Sport Management Review, 1(1), 45-76. https://doi.org/10.1016/S1441-3523(98)70099-3

Gibson, H. J. (2005). Sport tourism: Concepts and theories. An introduction. Sport in Society, 8(2), 133-141. https://doi.org/10.1080/17430430500101996

Gil, A. C. (2008). Métodos e Técnicas de Pesquisa Social (6 $6^{\mathrm{a}}$ ). Atlas.

Hall, C. M. (1992). Adventure, Sport and Health Tourism. In C. M. Hall \& B. Weiler (Eds.), Special Interest Tourism (pp. 141-158). Londres: Bellhaven Press.

Instituto Municipal de Turismo de Curitiba. (2016a). Da Copa do Mundo ao UFC, Curitiba se consolida como destino nacional.

Instituto Municipal de Turismo de Curitiba. (2016b). Pesquisa sobre o perfil, percepção e o impacto econômico do turista participante do UFC 198 - curitiba. https://turismo. curitiba.pr.gov.br/conteudo/dados-e-estatisticas/1724

Instituto Municipal de Turismo de Curitiba. (2016c). UFC confirma preparo de Curitiba para eventos e gera impacto de $R \$ 45$ milhões. https://www.curitiba.pr.gov.br/ noticias/ufc-confirma-preparo-de-curitiba-para-eventos-e-gera-impacto-de-r45-milhoes/39753

Instituto Municipal de Turismo de Curitiba. (2018). Instituto Municipal de Turismo quer impulsionar turismo de negócios. http://www.turismo.curitiba.pr.gov.br/noticias/ instituto-municipal-de-turismo-quer-impulsionar-turismo-de-negocios/205 
International Congress and Convention Association. (2018). The International Association Meetings Market 2018 - ICCA Statistics Report. https://www.iccaworld.org

Ishy, M. (1998). Turismo e Megaeventos Esportivos. Turismo em Análise, 9(2), 47-91.

Johner, M. P., \& Cunha, A. M. (2016). 0 Turismo esportivo, como novo atrativo e inovação de serviços da cidade de Porto Alegre: a experiência do Grêmio Arena Tour. Fólio Revista Científica Digital - Jornalismo, Publicidade e Turismo, 17(1), 95-110. https:// doi.org/10.15602/1981-3422/folio.v17n1p95-110

Kirilenko, A. P., \& Stepchenkova, S. O. (2017). Sochi 2014 Olympics on Twitter: Perspectives of hosts and guests. Tourism Management, 63, 54-65. https://doi.org/10.1016/j. tourman.2017.06.007

Lohmann, G., \& Netto, A. P. (2008). Teorias do Turismo. São Paulo: Aleph.

Lüdke, M., \& André, M. E. D. A. (2013). Abordagens qualitativas de pesquisa: a pesquisa etnográfica e o estudo de caso. In Pesquisa em Educacao: Abordagens Qualitativas. São Paulo: E.P.U.

Machete, R. (2011). Clima e turismo num contexto de mudanças ambientais. Finisterra, 46(91), 139-154. https://doi.org/10.18055/finis1330

Ministério do Turismo. (2016). Rio de Janeiro e São Paulo são as mais visitadas por estrangeiros. http://www.turismo.gov.br/ultimas-noticias/6512-rio-de-janeiro-esão-paulo-são-as-mais-visitadas-por-estrangeiros.html

Ministério do Turismo. (2017). Anuário Estatístico de Turismo 2017 - Ano base 2016 (Vol. 44). http://www.dadosefatos.turismo.gov.br/2016-02-04-11-53-05/item/347anuário-estatístico-de-turismo-2017-ano-base-2016/347-anuário-estatístico-deturismo-2017-ano-base-2016.html

Ministério do Turismo. (2019). Chegada de turistas internacionais. http://dados.turismo. gov.br/index.php/chegada-de-turistas-internacionais

Nakatani, M. S. M., Gomes, E. L., \& Nunes, M. P. (2017). Diferentes Olhares da Comunicação no Turismo: entendendo três localidades paranaenses como destino e produto turístico. Revista Turismo em Análise, 28(3), 474-491. https://doi.org/10.11606/ issn.1984-4867.v28i3p474-491

Nogueira, F. do A. (2006). Continuidade e descontinuidade administrativa em governos locais: fatores que sustentam a ação pública ao longo dos anos. Dissertação (Mestrado) - Escola de Administração de Empresas de São Paulo, Fundação Getúlio Vargas.

O Globo. (2016). Histórico: o impacto do UFC 198, na Arena da Baixada. https://oglobo. globo.com/esportes/historico-impacto-do-ufc-198-na-arena-da-baixada-19312760

Passos, D. de A., Prado, R. C., Marchi Júnior, W., \& Capraro, A. M. (2014). As origens do "vale-tudo" na cidade de Curitiba-PR memórias sobre identidade, masculinidade e violência. Movimento, 20(3), 1153-1170. https://doi.org/10.22456/19828918.42829

Pinheiro, P. M. de S. (2012). Planejamento e ações para o desenvolvimento do turismo no ambiente do futebol: Um estudo de Grêmio e Internacional de Porto Alegre. Dissertação (Mestrado em Turismo e Hotelaria) - Curso de Mestrado Acadêmico em Turismo e Hotelaria, Universidade do Vale do Itajaí.

Prefeitura Municipal de Curitiba. (2018). Setor turístico cresce com as temperaturas mais baixas. http://www.curitiba.pr.gov.br/noticias/setor-turistico-cresce-com-astemperaturas-mais-baixas/42783

Rabahy, W. A. (2019). Análise e perspectivas do turismo no Brasil. Revista Brasileira de Pesquisa em Turismo, 14(1), 1-13. https://doi.org/10.7784/rbtur.v14i1.1903 
Raupp, F. M., \& Beuren, I. M. (2006). Metodologia da pesquisa aplicável às Ciências Sociais. In Como Elaborar Trabalhos Monográficos em Contabilidade: Teoria e Prática (3ae ed.). São Paulo: Atlas.

Rocha, C. M., \& Fink, J. S. (2017). Attitudes toward attending the 2016 Olympic Games and visiting Brazil after the games. Tourism Management Perspectives, 22, 17-26. https:// doi.org/10.1016/j.tmp.2017.01.001

Rodrigues, E. A. P. C., Drula, A. J., \& Rechia, S. (2017). Do rubro-negro ao neutro da fifa: Uma análise das transformações dos estádios-sede da copa do mundo de 2014. Movimento, 23(4), 1283-1296. https://doi.org/10.22456/1982-8918.72230

Romano, F. S. (2018). Atratividade turística em estádios de futebol: visitação no estádio Arena Corinthians. Dissertação (Programa de Pós-graduação em Turismo) - Escola de Artes, Ciências e Humanidades, Universidade de São Paulo. https://teses.usp. br/teses/disponiveis/100/100140/tde-12122018-202316/publico/atratividade_ turistica_em_estadios_de_futebol.pdf

Romano, F. S., Tomazzoni, E. L., \& Uvinha, R. R. (2019). Megaeventos Esportivos no Brasil e o Plano Nacional de Turismo 2013-2016: As Metas de Expansão Turística. Rosa dos Ventos Turismo e Hospitalidade, 11(2), 454-475. https://doi.org/10.18226/21789061.v11i2p454

RPC. (2016). Curitiba é uma das cidades do país melhor preparada para receber turistas. https://www.negociosrpc.com.br/deolhonomercado/economia/curitiba-e-uma-dascidades-do-pais-melhor-preparadas-para-receber-turistas/

UFC. (2019). UFC 243 quebra recorde de público; Confira o Top 5. Ultimate Fight Championship. https://www.ufc.com.br/news/ufc-243-quebra-recorde-de-publico-confira-o-top-5

Uvinha, R. R. (2016). Turismo, Lazer e Megaeventos Esportivos no Brasil: relato de experiências sobre as Olimpíadas 2016. Revista Turismo e Desenvolvimento, 27(3), 714-731. https://doi.org/http://dx.doi.org/10.11606/issn.1984-4867.v27i3p714-731

Uvinha, R. R., Chan, C. S., Man, C. K., \& Marafa, L. M. (2018). Sport tourism: a comparative analysis of residents from Brazil and Hong Kong. Revista Brasileira de Pesquisa em Turismo, 12(1), 180-206. https://doi.org/10.7784/rbtur.v12i1.1374

Weed, M. (2006). Sports tourism research 2000-2004: A systematic review of knowledge and a meta-evaluation of methods. Journal of Sport and Tourism, 11(1), 5-30. https:// doi.org/10.1080/14775080600985150

Weed, M. (2008). Sports tourism experiences. Journal of Sport and Tourism, 13(1), 1-4. https://doi.org/10.1080/14775080802008876

Yin, R. K. (2014). Case study research design and methods (5aㅡ ed.). Thousand Oaks: Sage.

Recebido em: 24/11/2020

Aprovado em: 18/04/2021

\section{CONTRIBUIÇÕES}

Jonathan Rocha de Oliveira: Definição do problema de pesquisa e objetivos; Desenvolvimento da proposição teórica; Realização da revisão bibliográfica e fundamentação teórica; Coleta de dados; Análise de dados; Elaboração de tabelas, gráficos e figuras; Redação do manuscrito; Adequação do manuscrito às normas da RTA.

Bruna Opieco Pereira: Definição do problema de pesquisa e objetivos; Desenvolvimento da proposição teórica; Realização da revisão bibliográfica e fundamentação teórica; 
Escolha dos procedimentos metodológicos; Coleta de dados; Análise de dados; Realização de cálculos e projeções; Redação do manuscrito.

Riqueldi Straub Lise: Desenvolvimento da proposição teórica; Realização da revisão bibliográfica e fundamentação teórica; Escolha dos procedimentos metodológicos; Coleta de dados; Análise de dados; Revisão crítica do manuscrito; Redação do manuscrito.

André Mendes Capraro: Análise de dados; Revisão crítica do manuscrito. 